\title{
Construction of depth-discharge relation for inundation simulation
}

\author{
S. Kudo ${ }^{a}$, Yorozuya $^{a}$, H. Koseki ${ }^{a}$, Y. Iwami ${ }^{\text {a }}$ and M. Nakatsugawa ${ }^{\text {b }}$ \\ ${ }^{a}$ International Centre for Water Hazard and Risk Management, Public Works Research Institute \\ ${ }^{b}$ Graduate school of engineering, Muroran Institute of Technology \\ Email: s-kudou@pwri.go.jp
}

\begin{abstract}
This study aims to construct a depth-discharge relation for inundation simulation in the Mekong River considering hydraulic resistance. This relation links to the conveyance capacity of a river channel, one of the key components of inundation models, which means that understanding of the relation is necessary to conduct inundation simulation. A depth-discharge rating curve is constructed based on the simple assumption that discharge increases in a simple increasing function as depth increases. However, it is well recognized that this assumption is not valid in some cases: e.g., 1) rating curves constructed with only small-scale flood data are not always readily applicable to larger floods since extrapolation is often needed in this case, generally causing inaccurate estimation, and 2) rating curves cannot be maintained when river bed elevation changes, which means that they need to be checked periodically. One of the reasons for these cases is that hydraulic resistance varies as river bed shear stress changes during a flood. Accordingly, construction of the depth-discharge relation requires the knowledge of fluvial hydraulics, e.g., bed form and hydraulics resistance which is composed of velocity, water depth, hydraulic slope and bed material. A number of studies have been conducted on the relation between micro-scale bed form and hydraulic resistance. Engelund focused on the relation between dimensionless total and grain shear stress (the $\tau_{*}-\tau_{*}{ }^{\prime}$ relation). KishiKuroki included the concept of relative water depth in the $\tau_{*}-\tau_{*}{ }^{\prime}$ relation. They also formulated a bed roughness $\left(\mathrm{n}_{1}\right)$ for each bed form. Yamamoto developed diagrams which indicate the relation among velocity factor, dimensionless total shear stress, and relative water depth.
\end{abstract}

Aiming to construct the depth-discharge relation based on field observation data and the relation between micro-scale bed form and hydraulic resistance, the authors analyze $\tau_{*}-\tau_{*}$ ' relation by using observed data obtained by ADCP and the $\tau_{*}-\tau_{*}{ }^{\prime}$ relation proposed by Engelund. The target points of the river are selected from observation stations in Cambodia on the following conditions: 1) the river width is $1.0-2.0 \mathrm{~km}, 2$ ) the maximum water depth is $30-40 \mathrm{~m}$, and 3) the maximum discharge is $60,000 \mathrm{~m}^{3} / \mathrm{s}$ during a severe flood.

Based on the observed results, the $\tau_{*}-\tau_{*}{ }^{\prime}$ relation agrees with the one proposed by Engelund under the condition of that $n_{1}$ is identical to the bed roughness calculated with Manning's equation. The discharges calculated based on the $\tau_{*}-\tau_{*}{ }^{\prime}$ relation reproduce the discharges observed by ADCP in 2009. In addition, the calculated discharge with roughness composed of only grain roughness reproduces the peak discharge in 2011 estimated by the Mekong River Commission. The results will be useful to estimate discharges as a boundary condition. Moreover, the knowledge acquired in this study will help modeling bed roughness with respect to hydraulic force for further study related to inundation simulation.

Keywords: Hydraulic resistance, micro-scale bed form, field observation, Mekong River 


\section{INTRODUCTION}

Severe flood events occurred in the Mekong River in 2000 and 2011. The basin originates from Tibetan Plateau and the flow goes into South China Sea from Vietnam. The basin area is $805,604 \mathrm{~km}^{2}$. The flood in 2000 is regarded as the worst flood disaster in the 70 years and the flood in 2011 also as one of the most devastating, affecting 18 out of 24 provinces in Cambodia. The 2011 flood was caused by rainfall 1.2-1.8 times that in the average year. To prevent flood disasters from recurring in future, it is important to understand the behavior of such floods by observing hydraulic characteristics. A report about the 2011 flood published by the Mekong River Commission (MRC) describes hydraulic quantities such as water levels in several observation stations and maximum inundation area in the basin. Furthermore, the Mekong River Commission Secretariat (MRCS) conducted discharge observations during the flood season in 2009 to construct rating curves of discharge versus depth (H-Q curves) of several stations. H-Q curves are useful to calculate discharges from water levels and commonly used all over the world. However, they are not always effective to obtain accurate discharges particularly in cases in which water levels are extremely high, and require extrapolation to calculate discharges in such cases. Additionally, many observation stations calculate discharges by using more than two H-Q curves especially in the range of high water levels. One of the reasons for these difficulties with H-Q curves is that discharges change discontinuously due to changes in bed roughness during flooding.

A number of studies have been conducted regarding roughness change during flooding. Simons et al. (1961) discussed the relation among hydraulic quantities such as micro-scale bed form, Froude number and Darcy friction factor. Engelund (1967) formulated the $\tau_{*}-\tau_{*}{ }^{\prime}$ relation, assuming that dimensionless grain shear stress $\left(\tau_{*}{ }^{\prime}\right)$ is a simple increasing function of dimensionless total shear stress $\left(\tau_{*}\right)$. Kishi-Kuroki (1973) included relative water depth $(\mathrm{R} / \mathrm{d})$ as an explanatory variable in the $\tau_{*}-\tau_{*}{ }^{\prime}$ relation. Yamaguchi et al. (2003) and Izumi et al. (2006) discussed the hysteresis of the $\tau_{*}-\tau_{*}{ }^{\prime}$ relation with linear and weakly nonlinear analysis. Experimental research was also conducted in the Chiyoda experimental channel of the Tokachi River to observe bed form in a controlled environment (Kakinuma et al, 2013). Observed data at the Ishikari River during a flood in August 1981 was analyzed in terms of the $\tau^{*}-\tau^{*}$ relation (Hirai et al, 2014). Kudo et al. (2015) discussed a depth-discharge relation, employing the $\tau_{*}-\tau_{*}$ ' relation with data from discharge observations using floats in several rivers in Japan. However, a few studies have been conducted on analysis of hydraulic resistance in large-scale basins, using detailed data.

This study analyzed hydraulic resistance, i.e., the $\tau_{*}-\tau_{*}{ }^{\prime}$ relation, in the Mekong River, using data observed by MRCS and the Public Works Research Institute (PWRI) with acoustic Doppler current profiler (ADCP), and estimated discharges with the $\tau_{*}-\tau_{*}{ }^{\prime}$ relation, considering roughness change during flooding.

\section{DISCHARGE OBSERVATION}

\subsection{Observation by MRCS}

Twelve observation stations were selected, and discharge observations were conducted 24 times at each station by MRCS during the flood season in 2009. Observations at Venuai and Lumphat, located on upstream

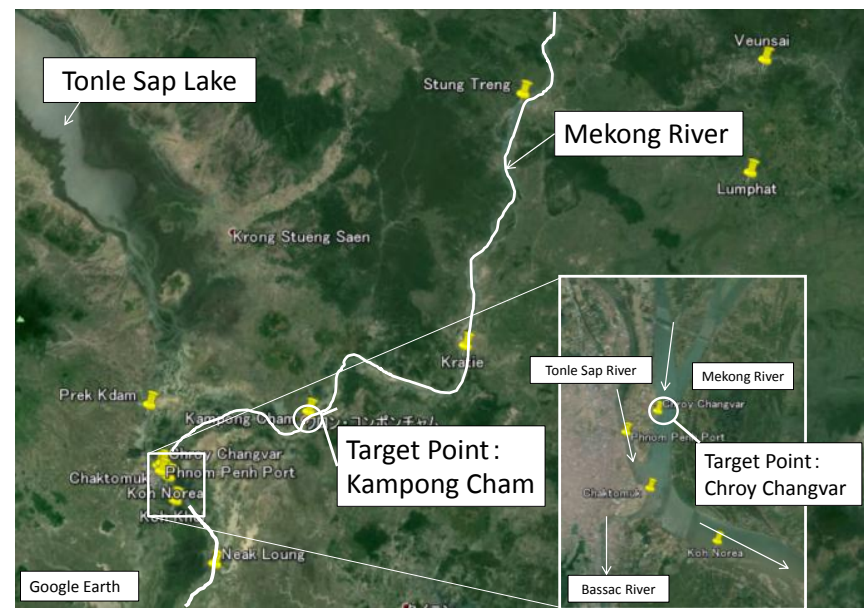

Figure 1. Observation stations and target points of this study

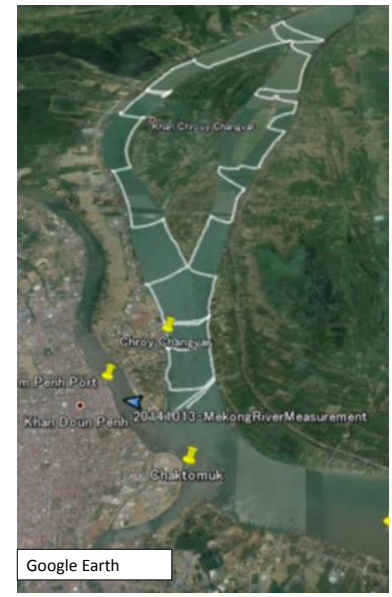

Figure 2. Boat path of observation by PWRI on 13 October 2014 
tributaries of the Mekong River (Figure 1), were conducted by using a current meter type, OSS-B1. An ADCP with a frequency of $600 \mathrm{kHz}$ was used at Stung Treng, Kratie and Kamgpong Cham. An acoustic Doppler profiler (ADP) with a frequency of $500 \mathrm{kHz}$ was used at the remaining seven stations. Chroy Changvar and Kampong Cham are selected as target points in this study.

\subsection{Observation by PWRI}

Discharge observations with a River Ray ADCP of $600 \mathrm{kHz}$ were conducted around Phnom Penh during the dry season in December 2013 and at the end of the flood season in October 2014. Figure 2 shows the boat path of the observation on 13 October 2014. The observation data collected immediately upstream of the confluence of the Mekong and Tonle Sap rivers are used as data at Chroy Changvar. Figure 3 shows observation with a River Ray ADCP. Since the water surface was calm even at the end of the flood season, data was obtained stably. Yorozuya et al. (2014) reported details about the observation around Phnom Penh using River Ray ADCP.

\section{ANALYSIS OF HYDRAULIC RESISTANCE}

This study focuses on the $\tau_{*}-\tau_{*}{ }^{\prime}$ relation, which is written as:

$$
\tau_{*}=\tau_{*}{ }^{\prime}+\tau_{*}{ }^{\prime \prime}
$$

Where $\tau_{*}, \tau_{*}{ }^{\prime}$ and $\tau_{*}{ }^{\prime \prime}$ are the dimensionless total shear stress, shear stress due to grain roughness, and shear stress due to bed form roughness, respectively.

Equation (1) means that $\tau_{*}$ is a simple superposition of $\tau_{*}{ }^{\prime}$ and $\tau_{*}{ }^{\prime \prime}$. When $\tau_{*}{ }^{\prime \prime}$ increases with development of micro-scale bed form, the ratio of $\tau_{*}{ }^{\prime}$ to $\tau_{*}$ decreases. Engelund (1967) derived the following equation for lower regime, assuming that $\tau_{*}{ }^{\prime}$ is a simple increasing function of $\tau_{*}$.

$$
\tau_{*}{ }^{\prime}=0.06+0.4 \tau_{*}{ }^{2}
$$

Kishi-Kuroki (1973) proposed equations of the $\tau_{*}-\tau_{*}{ }^{\prime}$ relation, which include the ratio of hydraulic radius to diameter $(\mathrm{R} / \mathrm{d})$ as an explanatory variable. The equations were derived from data that $\mathrm{R} / \mathrm{d}$ range is less than 2,000, whereas the $\mathrm{R} / \mathrm{d}$ of the data used in this study was about 40,000. Because our data exceeded the applicable range of the Kishi-Kuroki equations, equation (2) by Engelund was used in this study.

Takebayashi et al. (2009) surveyed bed material diameters at Chaktomuk, located immediately downstream of the confluence of the Mekong and Tonle Sap rivers, and found that the average grain diameter is about 0.5 $\mathrm{mm}$. Hence the analysis at Chroy Changvar used $0.5 \mathrm{~mm}$ as grain diameter. Water levels at Chaktomuk, Kampong Cham and Neak Loeung were used to calculate water surface slope.

Figure 4 shows the $\tau_{*}-\tau_{*}$ ' relation using the data obtained by MRCS and PWRI. Both data show the same tendency. Although the observed data differ from the $\tau_{*}-\tau_{*}{ }^{\prime}$ relation by Engelund when $\tau_{*}$ is below 0.4 , they agree well when it goes above 0.4. As mentioned above, the flow condition at Chroy Changvar was calm with the Froude number about 0.1 while $\tau_{*}$ was up to 1.0 because of deep water depth and small grain diameter. Figure 5 shows the $\tau_{*}-n$ relation. Two types of roughness are presented; one is calculated based on the theory of the $\tau_{*}-\tau_{*}{ }^{\prime}$ relation, and the other from Manning's equation. Both types match well with

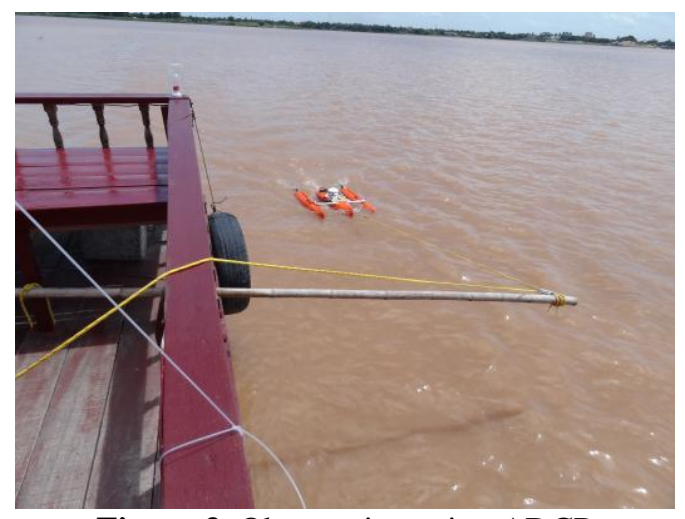

Figure 3. Observation using ADCP each other when $\tau_{*}$ is above 0.4. Figure 5 shows that $n$ decreases gradually with increment of $\tau_{*}$. Meanwhile, $n$ was estimated to be 0.035 when $\tau_{*}=1.0$ with a mechanical method using the height and wavelength of micro-scale bed form. This value almost agrees with the one in Figure 5.

\section{ESTIMATION OF DISCHARGE CONSIDERING HYDRAULIC RESISTANCE}

\subsection{Estimation using data in 2009}


Figure 6 shows changes in discharge calculated based on the theory of Engelund by using data in 2009 including water level and water surface slope. The discharge is calculated by multiplying observed water depth by estimated water velocity considering roughness change according to Engelund's theory. The calculation procedure is details are shown in Kudo et al (2015). Although the calculation needs water level data at Chroy Changvar, the data were not measured continuously in 2009. Therefore, the data were prepared by adding water levels at Chaktomuk and the difference in water level between the two stations. It is confirmed that the calculated discharge reproduce the observed discharge. In addition, the fact that discharge measurements were conducted through the entire flood season including the flood peak is confirmed. The depth-discharge relation in 2009 appears a counterclockwise loop (Figure 7), which comes from a seasonal fluctuation of water slope. Such a loop affects the accuracy of H-Q curves when they are constructed by using water levels and discharges collected at only one station. To cope with this problem, MRCS has constructed H-Q curves by employing water levels at two stations to incorporate the difference in water level into $\mathrm{H}-\mathrm{Q}$ curves.

The filled circles in Figure 7 (O) are discharges observed by PWRI in December 2013 and October 2014. A comparison of the discharges in 2009, 2013 and 2014 confirmed that the discharges in 2013 were lower than

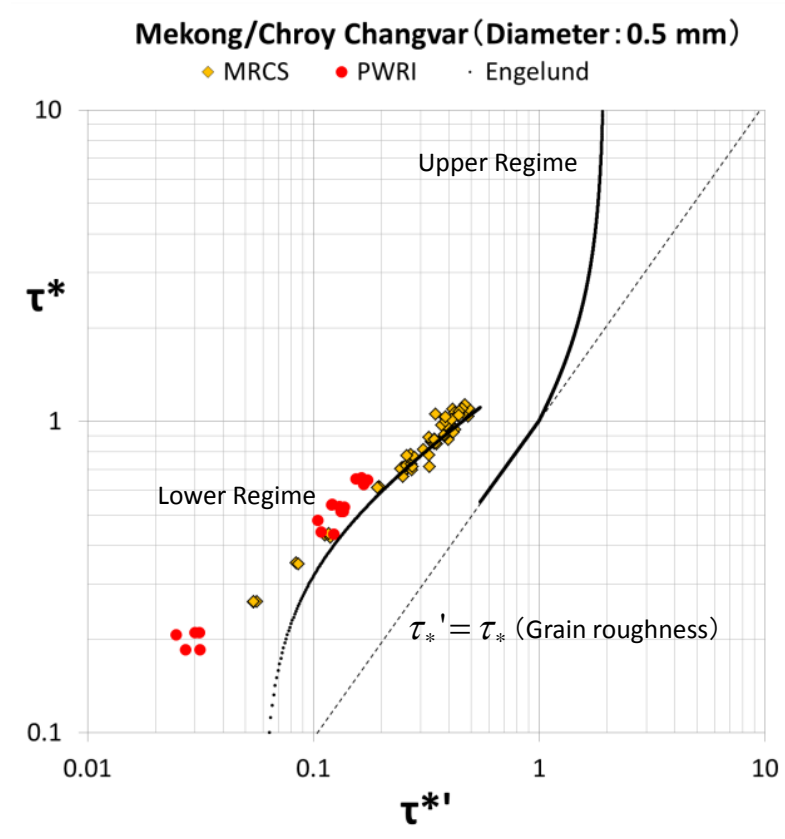

Figure 4. $\tau_{*}-\tau_{*}{ }^{\prime}$ relation at Chroy Changver

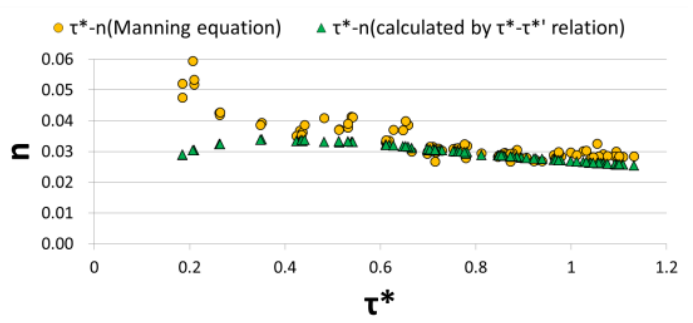

Figure 5. Comparison between roughness from Manning equation and the $\tau_{*}-\tau_{*}{ }^{\prime}$ relation those in 2009, and that the discharges in 2014 were higher than those in 2009. This kind of phenomena often occurs due to river bed change and other factors.

\subsection{Peak discharge estimation using the $\tau_{*}-\tau_{*}{ }^{\prime}$ relation}

In this section, we discuss changes in discharge when the water level exceeds the peak in 2009. Although $\tau_{*}$ reached 1.0 in this study, it cannot be anticipated how the $\tau_{*}-\tau_{*}{ }^{\prime}$ relation may change in the domain where $\tau_{*}$ is higher than 1.0. The $\tau_{*}-\tau_{*}{ }^{\prime}$ relation and roughness might change in response to lower regime, whereas there is a possibility that roughness might decrease suddenly. Furthermore, it is unrealistic that the $\tau_{*}-\tau_{*}{ }^{\prime}$ relation will shift to the upper regime domain because the Froude number is about 0.1 .

Hence, this study calculated discharges using two patterns of roughness. In one pattern, roughness changes according to lower regime; in the other, roughness is composed of only grain roughness. Water levels were set in the range from $9.0 \mathrm{~m} \mathrm{MSL}$ to $10.4 \mathrm{~m} \mathrm{MSL}$, which is the peak water level in 2000. The calculation results are shown in Figure 7 with diamonds $(\diamond)$ indicating calculated discharges assuming lower regime and triangles $(\triangle)$ indicating calculated discharges

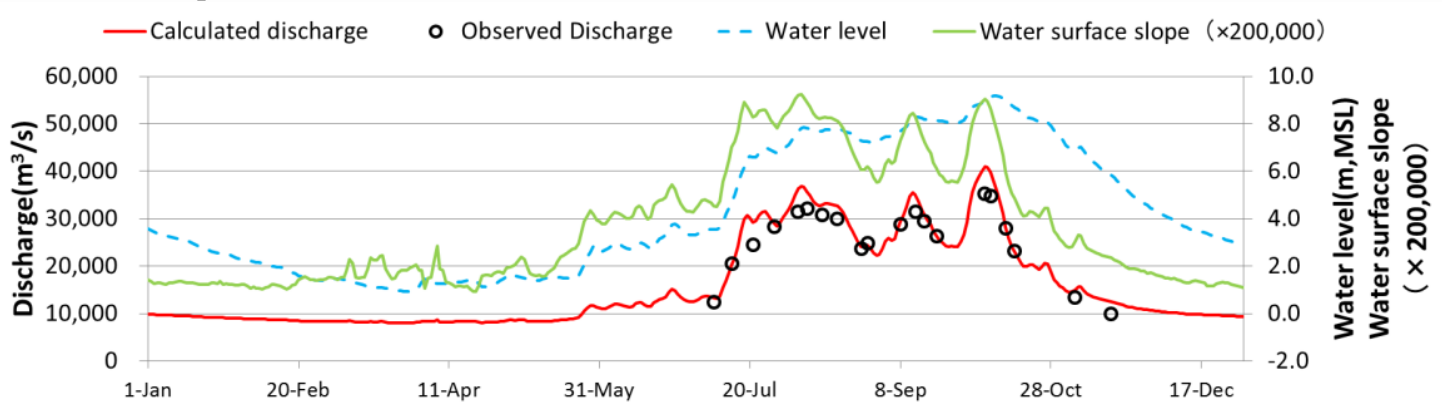

Figure 6. Comparison between calculated and observed discharges in 2009 at Chroy Changvar 
assuming only grain roughness. The lower-regime discharges align, following the general trend of the discharges of $2009(\square)$. In contrast, the grain-roughness discharges show an increasing trend that is discontinuous from the 2009 discharges. The grain-roughness discharge was calculated, assuming $\tau_{*}{ }^{\prime}=\tau_{*}$, as in Figure 4. The fact that the $\tau_{*}-\tau_{*}{ }^{\prime}$ relation $\left(\tau_{*}{ }^{\prime}=\tau_{*}\right)$ is far from observed data links to this discontinuous discharge trend. This kind of discontinuous change in discharge was observed in another observation station. During a discharge observation in Japan at the time of a flood due to a typhoon, the discharge changed sharply from $6,500 \mathrm{~m}^{3} / \mathrm{s}$ to $7,900 \mathrm{~m}^{3} / \mathrm{s}$ while the water level barely changed.

Although it cannot be concluded that this kind of phenomena occurred around Phnom Penh, it is important that this possibility is considered to estimate discharge. When the water level increased up to $10.4 \mathrm{~m} \mathrm{MSL}$, the discharge assuming lower regime is $60,401 \mathrm{~m}^{3} / \mathrm{s}$, and the discharge assuming only grain roughness is $76,427 \mathrm{~m}^{3} / \mathrm{s}$.

\subsection{Estimation of discharge in 2011}

Figure 8 shows three types of discharge calculated by using observed water levels, water surface slopes and other values. Each calculation was conducted based on a different condition. One calculation uses roughness assumed to change according to lower regime (discharge \#1). In another calculation, roughness is assumed to be composed of only grain roughness (discharge \#2). This calculation starts when the water level exceeds 9.0 $\mathrm{m}$ MSL. In the other calculation, discharge is calculated by using H-Q curves which include difference in water level as an explanatory variable constructed by MRCS (discharge \#3). The reason why discharge \#2 starts after the water level exceeded 9.0 m MSL is that the roughness was confirmed to change in response to lower regime at a water level of less than $9.0 \mathrm{~m}$ MSL which is the maximum water level in 2009. Discharge \#2 is calculated until the end of the year including the recession period to consider the hysteresis of the $\tau_{*}-\tau_{*}{ }^{\prime}$ relation. In general, roughness shows higher values when $\tau_{*}$ increases than when it decreases.

Discharges \#1 and \#3 are almost the same during the flood period. H-Q curves were constructed, using

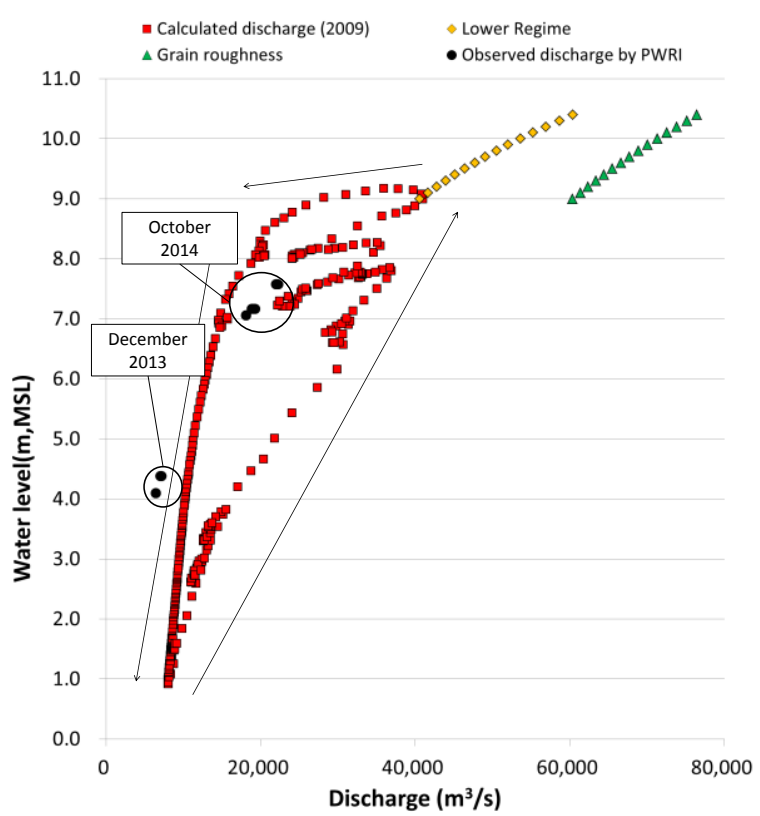

Figure 7. Depth-discharge relation at Chroy Changvar observed data in 2009 when the lower regime continued throughout the year. Since the H-Q curves were formed from data during the lower regime, discharge \#3 shows a very similar trend to discharge \#1, which assumes lower regime. Meanwhile, there is a difference between these two discharges during the dry season. This reflects the difference between the plotted and theoretical $\tau_{*}-\tau_{*}{ }^{\prime}$ relations in Figure 4, which needs further discussion.

Discharge \#2 is about $60,000 \mathrm{~m}^{3} / \mathrm{s}$ at the peak, and then decreases to $20,000 \mathrm{~m}^{3} / \mathrm{s}$ at the end of the year. The peak discharge at Kratie, located upstream of Chroy Changvar, is estimated at $63,250 \mathrm{~m}^{3} / \mathrm{s}$ on 24 September. The estimated discharge is shown in Figure 8 as the square $(\square)$. This value agrees with the discharge \#2, whereas disagreeing with that of discharge \#1. The flow discharge is predicted with an assumption of uniform flow condition. Influence of nonuniformity on flow discharge can be evaluated by:

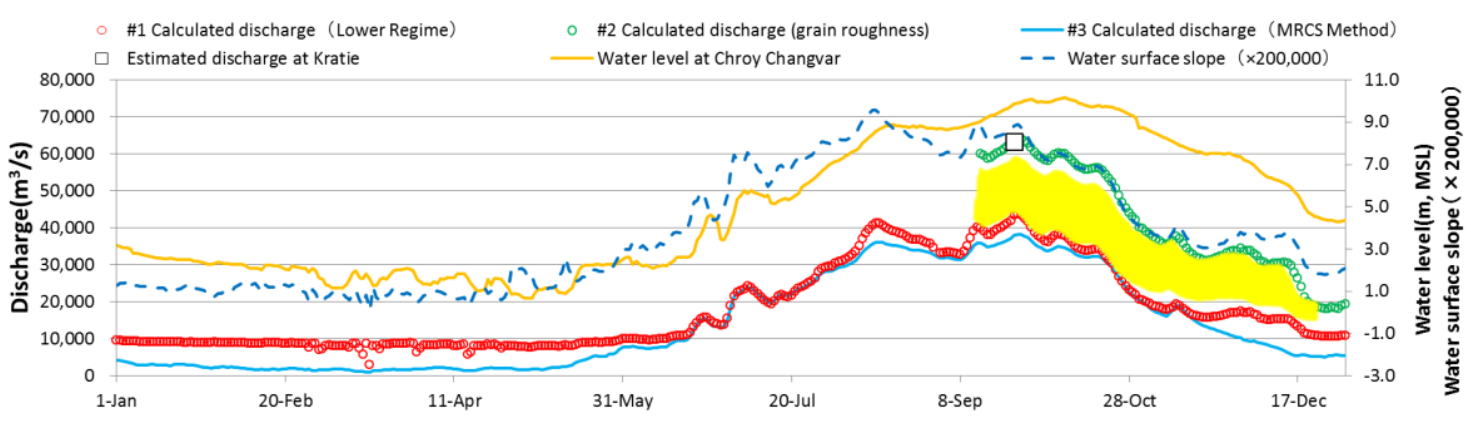

Figure 8. Calculated discharge in 2011 at Chroy Changvar 


$$
\frac{Q}{Q_{\mathrm{o}}}=\frac{1}{\sqrt{1-\frac{h^{1 / 3}}{n^{2} g} \frac{d h}{d x}}}
$$

This is derived by an equation of water surface profile, in which $Q_{0}$ is the uniform flow discharge, $Q$ is the flow discharge defined by energy slope, such as $i=\boldsymbol{n}^{2} \boldsymbol{Q}^{2} / \boldsymbol{h}^{10 / 3} \boldsymbol{B}^{2}$, and $h$ is water depth. $\frac{d \boldsymbol{h}}{d x}$ is estimated as $1 / 28,429$, assuming that wave length and height are $10,000 \mathrm{~m}$ and $1 \mathrm{~m}$ respectively. The ratio of $Q$ to $Q_{0}$ is 0.994 on 24 September 2011, when the peak discharge was observed at Kratie. Hence it's proved that the assumption of uniform condition doesn't have a considerable influence.

Note that the discharge at Kratie is only for a reference value because the inundation occurred in the flood plain downstream of Kratie, which affected the discharges at Chroy Changvar. In addition, the estimated value was calculated with extrapolation using H-Q curves. The discharges in 2011 are assumed to vary in the yellow-colored domain in Figure 8. To conduct further quantitative estimation, observation during a flood equal to the 2011 flood in scale is needed.

\section{IN CASE OF KAMPONG CHAM}

To establish a depth-discharge relation in the whole basin, analysis of the $\tau_{*}-\tau_{*}{ }^{\prime}$ relation at another point is required. To this end, Kampong Cham, located between Kratie and Chroy Changvar, is selected as the target point. Water slope used in calculation for Chroy Changvar is also used for Kampong Cham. The grain diameter of $1.0 \mathrm{~mm}$ is used because $0.5 \mathrm{~mm}$ is not suitable for reproduction of roughness. It is considered that the grain diameter in Kampong Cham should be larger than that in Chroy Changvar because Kampong Cham is located upstream of Chroy Changvar.

Figure 9 shows the $\tau_{*}-\tau_{*}{ }^{\prime}$ relation based on the data observed by MRCS. The alignment of the MRCS data agrees well with the theoretical $\tau_{*}-\tau_{*}{ }^{\prime}$ relation in the domain where $\tau_{*}$ is higher than 0.4 while disagreeing when $\tau_{*}$ is lower than 0.4. The difference between Chroy Changvar and Kampong Cham is that $\tau_{*}$ is smaller at Kampong Cham than at Chroy Changvar due to the difference in grain diameter. Figure 10 shows discharges in 2009. It is confirmed that the calculated and observed discharges in Figure 10 show a reasonable agreement during the flood season though the discharges in the dry season which is from November are overestimated.

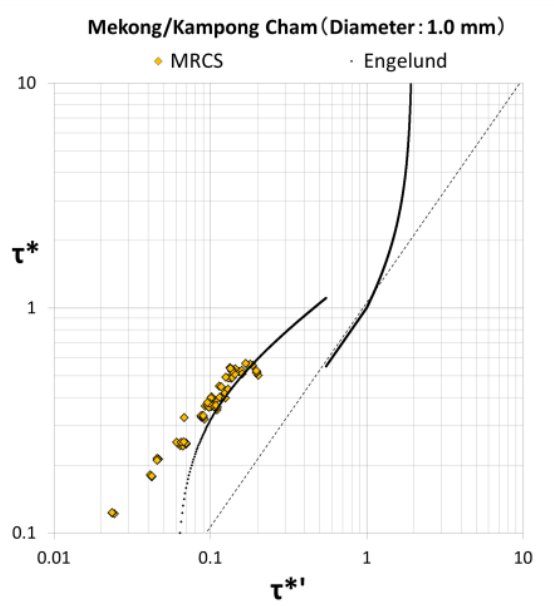

Figure 9. $\tau_{*}-\tau_{*}{ }^{\prime}$ relation at Kampong Cham

\section{CONCLUSION}

1) The $\tau_{*}-\tau_{*}{ }^{\prime}$ relation based on data observed by MRCS and PWRI shows a reasonable agreement with the theory of Engelund. The value $\tau_{*}$ increases up to 1.0 because of deep water depth and small grain diameter at the target points of this research.

2) Discharges calculated by using the $\tau_{*}-\tau_{*}{ }^{\prime}$ relation reproduced discharges observed by MRCS in 2009 successfully, especially in the flood season.

3) Discharges, when water level exceeds the peak in 2009, were estimated in two patterns: one used roughness assumed to change according to lower regime and the other used roughness composed of only grain roughness.

4) Discharges in 2011 are also estimated in three cases.

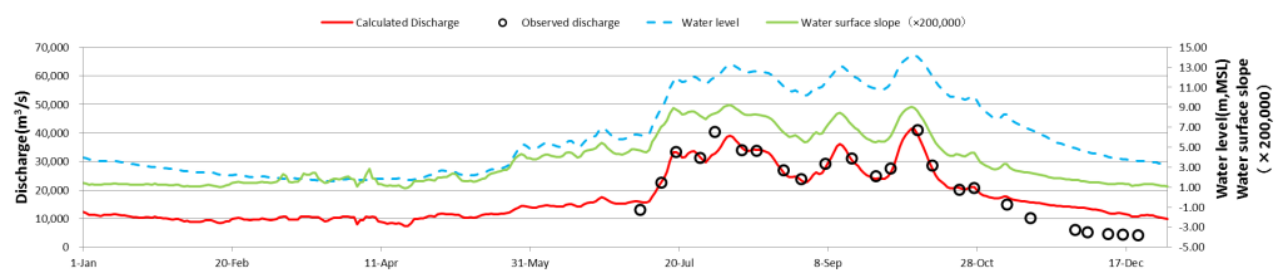

Figure 10. Comparison between calculated and observed discharge in 2009 at Kampong Cham 
Kudo et al., Construction of depth-discharge relation for inundation simulation

Estimated discharges at Kratie agreed with discharges calculated with only grain roughness.

5) Analysis of the $\tau_{*}-\tau_{*}{ }^{\prime}$ relation and discharge estimation was conducted for Kampong Cham. The results found that $\tau_{*}$ was relatively lower at Kampong Cham than at Chroy Changvar. The calculated discharges reproduced the observed discharges during the flood well whereas they were overestimated during the dry season.

The results of this study should be used for modeling hydraulic resistance to conduct inundation simulation. In particular, roughness change in every time step in inundation simulation will be calculated by $\tau_{*}-\tau_{*}{ }^{\prime}$ relation so that roughness change during flood can be reflected in the model.

\section{ACKNOWLEDGMENTS}

We would like to express our deepest gratitude to the Mekong River Commission Secretariat for provision of data, National Committee for Disaster Management for supporting our field survey and Dr. Shinji Egashira, Research and Training Advisor of ICHARM for giving us a lot of valuable advices for this study.

\section{REFERENCES}

Asian Disaster Reduction Center: Report 2002, http://www.adrc.asia/countryreport/KHM/KHMeng02/Cambodia_CR.htm

Engelund, F.(1967). Closure to "Hydraulic Resistance of Alluvial Streams," Journal of the Hydraulics Division, ASCE, Vol. 93, No. HY-4, pp. 287-296.

Hirai, Y, IZUMI, N and Ito, A (2014), ANALYSIS OF THE BEHAVIOR OF RIVER BED RESISTANCE IN THE SIMULTANEOUS WATER LEVEL OBSERVATIONS DURING ISHIKARI RIVER FLOOD IN AUGUST 1981 (in Japanese), Advances in River Engineering, Vol. 20, pp.235-240.

Izumi, N and Yamaguchi, S (2006). THE DUNE-FLAT BED TRANSITION REVISED (in JAPANESE), Journal of Japan Society of Civil Engineers B, Vol.62 No.4, pp.360-375.

Kakinuma, T, Inoue, T, Akahori, R and Takeda, A (2013), A RESEARCH ON THE RIVER BED RESISTANCE OF CHIYODA EXPERIMENTAL FLUME (in Japanese), Annual Journal of Hydraulic Engineering, JSCE, Vol.69, No.4, I_1087-I_1092.

Kishi, T and Kuroki, M (1973). Bed Froms and Resistance to Flow in Erodible-Bed Channels (I) -Hydraulic Relations for Flow over Sand Waves- (in Japanese), Bulletin of the Faculty of Engineering, Hokkaido University, 67, pp.1-23

Kudo, S, Yorozuya, A, Koseki, H and Iwami, Y (2015), STUDY ON CONSTRUCTION OF NEW DEPTHDISCHARGE RELATION FOR RIVER ADMINISTRATION (in Japanese), New phase of river discharge observation, Vol. 5, pp.14-21.

Mekong River Commission (2011). Flood Situation Report 2011, MRC Technical Paper, No.36.

Mekong River Commission Secretariat (2010), FINAL REPORT on IMPLEMENTATION OF DISCHARGE MEASUREMENTS ON THE MEKONG MAINSTREAM, THE TONLE SAP RIVER AND BASSAC RIVER IN THE KINGDOM OF CAMBODIA.

Simons, D. B. and Richardson, E.V.(1961). Forms of bed roughness in alluvial channels, Journal of the Hydraulics Division, Proc. ASCE, Vol. 87, No.3, pp. 87-105.

Takebayashi, H, Nakamoto, T and Fujita, M (2009). Sediment Transport Characteristics on Bed with Cohesive and Non-cohesive Materials in Tonle Sap River (in Japanese), Annuals of Disas. Prev. Res. Inst., KyotoUniv., No.52, pp.637-645.

United Nations in Cambodia (2011). CAMBODIA - Flood Season Situation Report \#8.

Yamaguchi, S and Izumi, N (2003). SUBCRITICAL BIFURCATION OBSERVED IN THE TRANSITION BETWEEN DUNE AND FLAT BED REGIMES (in Japanese), Journal of Japan Society of Civil Engineers, No.740/II-64, pp.75-94.

Yorozuya, A, Motonaga, Y and Iwami, Y(2014), NEED TO KNOW HOW TO CONDUCT ADCP MEASUREMENT IN RIVERS OUTSIDE OF JAPAN AND PRELIMINARY RESULTS (in Japanese), New phase of river discharge observation, Vol. 4, pp.48-56. 